\title{
Sources of information in metamemory: Judgments of learning and feelings of knowing
}

\author{
BENNETT L. SCHWARTZ \\ Florida International University, Miami, Florida
}

\begin{abstract}
Metamnemonic judgments probe people's awareness of their own memory processes. The research reviewed here is an examination of the sources of information that subjects use to make judgments of learning (e.g., paired-associate judgments, ease-of-recognition predictions, free-recall judgments), and feelings of knowing (e.g., speeded strategy decisions, tip-of-the-tongue states, feeling-of-knowing judgments). The general pattern in the data suggests that subjects use different sources of information to form these judgments. Target-based sources appear to be important in judgments made at the time of acquisition, whereas cue-based judgments appear to be important in judgments made at the time of retrieval. In general, these sources of information serve as useful heuristics, and metamnemonic judgments tend to be accurate.
\end{abstract}

Implicit in discussions of metamemory is the fallible nature of human memory. Unlike a computer, a person may not be able to retrieve information under certain circumstances. If, once studied, an item remained in memory and was always retrievable, there would be no need for a system to monitor and control learning and behavior. However, there is much research that demonstrates the fallibility and context specificity of human memory (e.g., Bjork \& Bjork, 1992; Tulving, 1983; Tulving \& Pearlstone, 1966). Thus, metamnemonic judgments indicate how well target items are either available or accessible in memory. For instance, a student may be able to retrieve an answer now, but metamnemonic judgments assess whether the item will be retrievable at some future date. Similarly, at test, a student may decide that even though he or she may not know an answer now, he or she has a high feeling of knowing for the item, and the student may choose to spend more time trying to retrieve the item later. Furthermore, metamnemonic judgments may also inform strategy decisions, such as whether to retrieve an answer from memory or attempt to reason it out (Miner \& Reder, 1994).

The focus here will be on judgments that concern memorability at a future date, or prospective monitoring (see Nelson \& Narens, 1990). Prospective monitoring

I gratefully acknowledge the support of National Institute of Mental Health Grant MH48066-04 to Janet Metcalfe. I thank Janet Metcalfe, Robert Bjork, and Elizabeth Bjork for useful discussion leading up to this project. I thank Ron Fisher, John Dunlosky, Tom Nelson, Asher Koriat, John Gardiner, and one anonymous reviewer for their comments on an earlier version of this manuscript. Finally, I thank my parents, Carol H. Schwartz and Foster Schwartz for all their help and guidance over the years. Requests for reprints should be sent to B. Schwartz, Department of Psychology, Florida International University, University Park, Miami, FL 33199. has been the classic domain of metamemory (e.g., Arbuckle \& Cuddy, 1969; R. Brown \& McNeill, 1966; Hart, 1965). Metamemory, broadly defined, includes other judgments, such as reality and source monitoring (Johnson, Hashtroudi, \& Lindsay, 1993; Johnson \& Raye, 1981), retrospective confidence judgments (Kelley \& Lindsay, 1993), "don't know" judgments (Glucksberg \& McCloskey, 1981; Kolers \& Palef, 1976), hindsight judgments (Fischhoff, 1975), and judgments of subjective experience (Gardiner \& Java, 1993; Rajaram, 1993). The reason for the current focus on prospective judgments is that they share a common feature, namely, the prediction of future memory performance.

The tasks that are used in the study of prospective metamemory (henceforth, metamemory) will be described with respect to their similarities and differences. The differences are emphasized, because there has been a tendency to group various metamnemonic judgments together, and this has led to confusion. In fact, the tasks are quite different from each other both theoretically and methodologically. Following Nelson and Narens (1990), metamemory is divided into judgments made during acquisition of knowledge (judgments of learning, or JOLs) and judgments made at the time of retrieval (feelings of knowing). Judgments of learning include ease-oflearning judgments (Leonesio \& Nelson, 1990; Underwood, 1966), paired-associate JOLs (Arbuckle \& Cuddy, 1969; Leonesio \& Nelson, 1990), ease-of-recognition judgments (Begg, Duft, Lalonde, Melnick, \& Sanvito, 1989), and free-recall JOLs (Groninger, 1979; Mazzoni, Cornoldi, \& Marchitelli, 1990). Those made at the time of retrieval include speeded strategy decisions (Reder, 1987, 1988; Reder \& Ritter, 1992), tip-of-the-tongue judgments (R. Brown \& McNeill, 1966), and feeling-ofknowing judgments (Hart, 1965; Nelson, Leonesio, Shimamura, Landwehr, \& Narens, 1982). 
A second reason for distinguishing between judgment tasks is that the processes underlying the tasks may tap different sources of information. The sources of information fall into two broad categories-target-based sources and cue-based sources. These two sources implicate two different classes of mechanisms, referred to as direct-access mechanisms and inferential mechanisms (see Koriat, 1993; Krinsky \& Nelson, 1985; Nelson, Gerler, \& Narens, 1984). Direct access means that people monitor the specific memory representation of an item when making metamnemonic judgments. Thus, direct-access mechanisms imply that people rely on target-based information. Inferential mechanisms mean that people draw on information other than the specific representation to form the judgment. This information can be target-based or cue-based. Target-based sources include the ease of processing of targets, the amount of partial information generated, or interference from blocking material. The most prominent of the cue-based sources is cue familiarity (Metcalfe, 1993; Reder, 1987; see also Koriat \& Lieblich, 1977, for the historical introduction of this idea), but other cue-based sources may exist as well, including domain knowledge (Glenberg, Sanocki, Epstein, \& Morris, 1987; Nelson et al., 1984; Reder, 1987) and social desirability (Costermans, Lories, \& Ansay, 1992; Nelson et al., 1984). The position advanced here is that there is little support for a direct-access view. Rather, it appears that subjects can, and do, use a variety of cue- and target-based inferential sources to make metamnemonic judgments.

Because the sources of information are not mutually exclusive, they may act in concert to influence metacognitive judgments. Nelson and Narens (1990) stress the multidimensional basis for judgments, and there are data to support more than one source for each kind of judgment. For example, both cue familiarity and blocking from interfering items (target based) may act on tip-ofthe-tongue experiences (Metcalfe, Schwartz, \& Joaquim, 1993; Smith, 1994). Under certain circumstances, however, each source may operate alone. For instance, targetbased sources influence JOLs (Begg et al., 1989; Dunlosky \& Nelson, 1992, 1994), but they do not influence speeded strategy decisions (Reder, 1987; Reder \& Ritter, 1992). Therefore, it is important to delineate the conditions and tasks under which each of the sources acts.

\section{THEORETICAL APPROACHES}

Nelson and Narens $(1990,1994)$ and Miner and Reder (1994) have examined functional issues in metacognition-specifically, the efficacy of monitoring memory, and the role of metacognitive control in memory behavior. Nelson and Narens argue that the ability to make metamnemonic judgments arises out of the need to monitor and control mnemonic behavior. Miner and Reder argue that metacognition allows people to choose appropriate cognitive strategies, such as whether to retrieve from memory. In addition, there have been recent attempts to explore the underlying mechanisms and processes in metacognition, most notably by Metcalfe (1993, 1994) and Koriat (1993, 1994). Metcalfe (1993) has argued that structures that may have evolved to control storage in episodic memory can be modified to elicit feelings of knowing. Koriat (1993) presented a process model to show how people make feeling-of-knowing judgments that are based on inferences drawn from partial retrieval.

In contrast to the functional and structural approaches, in the present paper I examine prospective metamemory from an attributional approach. Jacoby, Kelley, and Dywan (1989) argue that people experience a subjective state of "pastness" only after making attributions (or inferences) that are based on current processing. They demonstrate situations in which subjects falsely infer "pastness" because they attribute fluent processing to the effects of memory. Similarly, the argument here is that people make attributions about future memorability on the basis of available information. This approach focuses on the internal and external sources of information that subjects use to form metamnemonic judgments. This implies specifying what information is used, rather than considering how that information is used (but see Koriat, 1993, and Metcalfe, 1993, for theories of how the judgments are derived). The attributional approach allows us to specify what information is brought to bear, either consciously or nonconsciously, by the learner.

The attributional approach stands in contrast to directaccess target-strength views (e.g., Burke, MacKay, Worthley, \& Wade, 1991; Hart, 1967a). According to direct-access approaches, subjects' judgments are based on access to the memory trace. The direct-access view has two important implications. First, because the judgments are based on the strength of a memory trace, any variable that acts to increase memorability will also increase the magnitude of the metamnemonic judgment (provided the judgments occur on an entire set, and not just on unrecalled items). Second, the judgments should always be above chance at predicting later criterion performance. In contrast, an attributional approach allows for the possibilities of dissociating memory and judgment and below-chance prediction. Indeed, it is possible to manipulate the information available to the subject at the time of making the judgment independently of memorability for the target (e.g., Reder, 1987). Moreover, there may be tasks for which subjects use the wrong source of information to make predictions, and therefore they mispredict future performance (Schwartz \& Bjork, 1993).

The attributional approach is similar to and compatible with recent heuristic views of metacognition (Koriat, 1993; Metcalfe et al., 1993; Reder \& Ritter, 1992). Heuristic views suggest that the basis for judgments is correlated with performance on a criterion task. Thus, judgments tend to be above chance at predicting later performance, but they need not be. The differences between the attributional and heuristic views are subtle. Heuristic views suggest that people use a rule, such as assessing cue familiarity, to determine their feeling of knowing. The at- 
tributional view suggests that people use whatever sources of information are available to arrive at the judgment. Thus, when only cue information is available, cue familiarity may influence judgments. But when more sources are available, such as partial target information, these sources will also exert an influence on the judgment.

\section{SOURCES OF INFORMATION IN METAMEMORY}

Nelson and Narens (1990) introduced the idea of the "metacognitive library," a hypothetical cognitive structure that maintains strategies that subjects may implement to assess their state of learning at a given time. Either consciously or nonconsciously, subjects select relevant sources from the library and use them to form the judgment. Because Nelson and Narens (1990) were more concerned about issues of monitoring and control in metacognition, they did not consider the content of the libraries in detail. The present review explores what may be the contents of these libraries, how subjects choose a given source, and the consequences of this decision.

The format for this review will be to discuss the sources of information that may underlie each judgment. Equally crucial is the relation between sources of information and whether the judgments are accurate (i.e., above chance) at predicting performance (Koriat, 1993). The crux of the argument advanced here is that metamnemonic judgments are based on sources that are correlated with memory variables, and thus the judgments will be above chance at predicting performance. However, it is also important to explain why metamnemonic judgments are not perfect (Nelson \& Narens, 1990), why some classes of judgments lead to higher accuracy than others, and why metamnemonic accuracy may be close to nil under some circumstances.

\section{Target-Based Sources}

Hypotheses based on target-based sources state that metamnemonic judgments derive from the retrieval process, the products of the retrieval process, or inferences based on the outcome of retrieval. Hypotheses concerning direct-access mechanisms suggest that subjects monitor unrecalled or to-be-recalled information. The inferential target-based hypothesis states that subjects make inferences that are based on available (i.e., already retrieved) target information.

\section{Direct-Access Approaches}

Target-strength views. The target-strength view states that subjects can directly monitor the availability of a given memory trace (Hart, 1967a). This hypothesis suggests that metamnemonic judgments are a direct memory test, akin to recall or recognition. According to Hart (1967a), a hypothetical "feeling-of-knowing" threshold occurs intermediately between a recall and recognition threshold. As such, variables that influence memorability should also influence judgments. Burke et al. (1991) argue that activation of nodes in semantic memory may provide a basis for some judgments.

\section{Inferential Approaches to Target-Based Sources}

Products of retrieval. This view has been referred to as the "no magic hypothesis" (Nelson \& Narens, 1990), and it also constitutes part of the basis for Koriat's (1993) "accessibility heuristic" theory. The products-ofretrieval hypothesis states that subjects make their metamnemonic judgments on the basis of retrieved information (Koriat, 1993; Nelson \& Narens, 1990). This hypothesis assumes that only retrievable information is used in making judgments (Nelson \& Narens, 1990). Koriat (1993) suggested that subjects make inferences on the basis of partial information, correct or incorrect, to determine their feeling of knowing. For instance, a subject may not recall an item in memory, but he or she may be able to recall the first letter, how many syllables it has, or what it means, and this partial or related information may be critical in forming metamnemonic judgments. However, the subject does not have special access to whether this information is correct (see Tulving, 1983, for a similar view).

Ease of processing. Begg et al. (1989) argue that ease of processing is used as a heuristic in making JOLs and predicting old/new recognition. In this theory, the speed at which cue or target information is processed is used as a source to infer a metacognitive judgment. The products-of-retrieval and the ease-of-processing explanations both involve nonanalytic judgments (see Jacoby \& Brooks, 1984; Jacoby \& Kelley, 1987). This means that, because subjects do not have direct access to their memory "state," they must rely on available information in order to make an attribution about the memory state. Furthermore, Koriat (1993) has argued that this process invokes an "unmediated feeling" that subjects rely on to determine future memorability. Thus, subjects may often "feel" that an item is memorable.

\section{Cue-Based Sources}

The cue familiarity hypothesis has received attention in recent work (Metcalfe, 1993; Metcalfe et al., 1993; Miner \& Reder, 1994; Reder, 1987, 1988; Reder \& Ritter, 1992; Schwartz \& Metcalfe, 1992). The cue familiarity hypothesis states that subjects rely on recognition of the cue to judge future memorability of the target. In the present context, cues will be defined as nontarget information that is present at the time of judgment. According to cue familiarity, it is not the retrieved information that provides the basis for the judgment, but is the stimulus information available to the subject. This hypothesis suggests that feelings of knowing may not be dependent on the processes of retrieval, and, as a result, it may be possible to dissociate memory and metamnemonic judgments.

Cue familiarity in metamemory bears a striking resemblance to the effects of prior exposure in other domains of subjective experience. Familiarity has been 
shown to affect a great number of memory processes, including recognition (Jacoby, 1991; Mandler, 1980), fame estimates (Jacoby, Woloshyn, \& Kelley, 1989), truth estimates (Begg, Anas, \& Farinacci, 1992), and feeling of knowing (Metcalfe et al., 1993; Reder, 1987; Reder \& Ritter, 1992; Schwartz \& Metcalfe, 1992). It is unclear how these subjective experiences are related. Recent discussion has focused on the perceptual or conceptual basis for familiarity (see Atkinson \& Juola, 1973; Jacoby, 1991; Jacoby, Woloshyn, \& Kelley, 1989; Mandler, 1980; Metcalfe, 1993, for views of familiarity).

\section{MEMORY JUDGMENT TASKS}

Nelson and Narens (1990) divide the tasks used in metamemory into judgments made at acquisition (during study) and those made at the time of retrieval (at test). Judgments made at acquisition concern the subjective difficulty of the items to be remembered, how much study may be required to learn them, and whether the items have been learned sufficiently to allow correct performance on a later test. For judgments made at the time of retrieval, the subject is asked whether he or she can recall or recognize the item at that time, or at some future time, often in the presence of additional cues (see Table 1 for an outline of judgments, the tasks they predict, and the sources of information that may influence them). As will become apparent, when subjects make judgments at acquisition, they rely on sources that are different from those used at retrieval.

\section{At the Time of Acquisition: Judgments of Learning Ease-of-Learning Judgments}

Ease-of-learning judgments are made just prior to a study trial. Subjects are asked to make an immediate assessment of how much study will be required to learn presented information, typically, cue-target pairs (Leonesio and Nelson, 1990; Underwood, 1966). As such, Nelson and Narens (1990) consider these judgments to be preacquisition judgments. Although little research has been done to directly address this kind of judgment, Underwood (1966) showed that these judg- ments were above chance in predicting learning rates. Furthermore, Leonesio and Nelson found that ease-oflearning judgments showed low intercorrelations with other metamnemonic judgments, such as feeling-ofknowing judgments and JOLs, suggesting that the sources for these metamnemonic judgments are not identical. In the Nelson-Narens (1990) framework, ease-of-learning judgments occur in advance of learning, and they allow the subject control in determining allocation of study time. No research has explicitly considered what sources subjects use to make these judgments.

\section{Paired-Associate Judgments of Learning}

Recent attention has focused on JOLs (Begg et al., 1989; Dunlosky \& Nelson, 1992, 1994; Nelson \& Dunlosky, 1991, 1992; Nelson \& Leonesio, 1988; Spellman \& Bjork, 1992). However, JOLs have a relatively long history (Arbuckle \& Cuddy, 1969; King, Zechmeister, \& Shaughnessy, 1980; Lovelace, 1984). They require subjects to decide whether they will recall a target at a later point in time. Important features of paired-associate JOLs are that they are made at the time of study on cue-target pairs, and they involve a prediction of later memory performance, usually cued recall or cued recognition. Furthermore, paired-associate JOLs differ from feeling-of-knowing judgments in two respects. JOLs are made at the time of acquisition and are made on all items, whereas feeling-of-knowing judgments are made at the time of test and are usually restricted to unrecalled items (but see Narens, Jameson, \& Lee, 1994, for an alternative analysis).

Two types of paired-associate JOLs will be distinguished here. In cue-target JOLs, (or stimulus-response JOLs; Dunlosky \& Nelson, 1992) the subject is asked to determine future retrievability of the target when presented with both the cue and the target of a to-be-learned pair. In cue-only JOLs (stimulus-alone JOLs; Dunlosky \& Nelson, 1992), subjects are presented with the cue only at the time of judgment, and they must decide the future retrievability of the target. Dunlosky and Nelson (1992) have examined how cue-only and cue-target

Table 1

\begin{tabular}{|c|c|c|c|c|}
\hline Task & Stimulus & Set of Items & Usual Prediction & Possible Source \\
\hline \multicolumn{5}{|l|}{ Acquisition } \\
\hline Cue-only JOLs & cue- & all & recall & $\begin{array}{l}\text { products of retrieval } \\
\text { cue familiarity }\end{array}$ \\
\hline Cue-target JOLs & cue-target & all & recall & memory strength \\
\hline EOR judgments & target & all & recognition & ease of processing \\
\hline \multicolumn{5}{|l|}{ Retrieval } \\
\hline Speeded decisions & cue- & all & recall & cue familiarity \\
\hline TOT & cue- & unrecalled & recall & $\begin{array}{l}\text { cue familiarity; } \\
\text { blocking }\end{array}$ \\
\hline FKJ & cue- & unrecalled & recognition & $\begin{array}{l}\text { cue familiarity; } \\
\text { accessibility }\end{array}$ \\
\hline
\end{tabular}

Note-JOLs, judgments of learning; EOR, ease of recognition; TOT, tip of the tongue; FKJ, feeling-of-knowing judgments. 
JOLs differ with respect to the accuracy with which the judgments predict later cued-recall performance. Dunlosky and Nelson (1994) show that each type of JOL may be influenced by different variables. In the present review, the two judgments will be considered together to underscore how slight differences in task can result in big differences in underlying sources.

Products of retrieval. There is now much evidence to support the hypothesis that people use inferences based on target-based information when forming cueonly JOLs (Begg et al., 1989; Dunlosky \& Nelson, 1994; Narens et al., 1994). Support for this idea derives from an initial finding that delayed cue-only JOLs showed better accuracy than immediate cue-only JOLs (Nelson \& Dunlosky, 1991). In trying to explain this phenomenon, Dunlosky and Nelson $(1992,1994)$ introduced a products-of-retrieval theory. In this section, the "delayedJOL effect" will be described, then the Dunlosky and Nelson (1992) hypothesis will be discussed, and, finally, data that directly support a target-based view will be discussed.

Following Nelson and Dunlosky (1991), Dunlosky and Nelson (1992) asked subjects to study unrelated cue-target pairs (e.g., OCEAN-TREE). Some of the subjects made JOLs in the presence of only the cue, and others made JOLs in the presence of both the cue and the target. Crossed with this variable was the delay between studying and making the judgment. For some items, the subject was presented with the judgment trial immediately following the study trial, whereas for other items, there was a delay of at least 10 other items. Dunlosky and Nelson (1992) found that for cue -target JOLs, there was no improvement in accuracy from the immediate to delayed condition, but with cue-only JOLs, the delayed judgments were considerably more accurate than the immediate judgments (gamma correlation $=.93$ for delayed, .45 for immediate). Nelson and Dunlosky (1991) labeled this difference between the immediate and the delayed cue-only JOLs the delayed-JOL effect.

Dunlosky and Nelson (1992) suggested a products-ofretrieval hypothesis that they call the monitoring-dualmemories hypothesis. In this view, subjects make JOLs on the basis of retrieved information that becomes active in short-term memory. In delayed cue-only JOLs, this information is likely to be highly similar to information that the subject will have available at the time of test. Thus, cue-only JOLs tend to show high accuracy when the JOL is delayed. However, in immediate cue-only JOLs and cue-target JOLs, target information may be available in short-term memory because of recent exposure, and not because of its production in retrieval. This "noise" from recent exposure tends to reduce the accuracy of the JOLs.

In the framework being developed here, Dunlosky and Nelson's (1992) view suggests that subjects rely on retrieved information to infer future memorability. Thus, variables that affect target information and its retrieval will affect the magnitude of cue-only JOLs. This is exactly what the empirical literature suggests. For exam- ple, King et al. (1980) suspected that when JOLs are elicited after previous testing, an additional source of information becomes available, namely, prior performance. Thus, if a subject can recall how he or she did on an earlier test of the particular item, a more accurate assessment of later performance can occur. To test this hypothesis, they compared the accuracy of judgments when subjects alternated between study and test of cuetarget pairs before making a judgment with a condition in which they studied only the cue-target pairs before making the prediction. Accuracy was higher when the subjects were given test opportunities prior to making the judgments. King et al. concluded that prior knowledge of performance can influence judgments. In the present context, these results support the contention that JOLs are based on the retrieval of target information.

Narens et al. (1994) examined the role of target information in JOLs. In their study, subjects studied word pairs (e.g., GARDEN-TRUCK). After a 3- to 5-min delay, they saw the cue word again. The subjects were then given a masked presentation of the correct target, the cue word, or an unrelated word. With masked presentation, they could not identify the target word. The subjects then made cue-only JOLs. Target priming, but not cue priming, increased JOLs relative to the unrelated prime condition. Thus, target information appears to play a role in JOLs, which is consistent with Dunlosky and Nelson's (1992) products-of-retrieval view-although Narens et al.'s data do not rule out the directaccess view.

Begg et al. (1989) examined potential sources of information in cue-only JOLs (which they called memory predictions). In their study, some subjects used interactive imagery to encode items, some used separate imagery to study pairs, and some used either interactive or separate imagery, depending upon a prearranged cue (the mixed condition). After studying all the pairs, the subjects reviewed the cues and made predictions of later recall (thus, these were equivalent to Nelson and Dunlosky's, 1992, delayed JOLs). Begg et al. (1989) found that, as expected, the subjects recalled more when they studied with interactive imagery than when they studied with separate imagery. Furthermore, JOLs were higher when the pair was studied with interactive imagery than when it was studied with separate imagery. Thus, it appears that subjects are sensitive to differences produced by the imagery instructions when they make JOLs. The results from Begg et al. (1989) support a target-based explanation of cue-only JOLs, because the targets with stronger memory representations (imagery items) received higher JOLs.

Dunlosky and Nelson (1994) recently replicated Begg et al.'s (1989) Experiment 2. They looked at the effects of imagery and rote encoding strategies on learning cue-target pairs, and they also varied the timing of cueonly JOLs - immediately after learning or after a delay. The experiment yielded several intriguing results. First, the delayed-JOL effect was replicated. Accuracy was better for the later judgments, regardless of encoding 
strategy. Second, when they compared imagery and rote encoding conditions, they found that the magnitude of JOLs increased, across delay, when the cue-target pairs were learned using imagery.

In a second experiment, Dunlosky and Nelson (1994) compared massed and distributed practice in learning cue--target pairs. For half of the items, subjects were given two successive study opportunities, and for the other half, they studied eight other items before presentation of the second repetition. As expected, recall was higher for the targets learned under distributed conditions than for those learned under the massed conditions. Dunlosky and Nelson (in press) also found that both immediate and delayed cue-only JOLs were higher in the distributed condition than in the massed condition. Both of these experiments support the role of target-based sources in JOLs.

Dunlosky and Nelson (1994) also looked at the distribution of JOLs across the immediate and delayed condition. They plotted the magnitude of the judgment on the $x$-axis and the proportion of items that received a given judgment on the $y$-axis (see Figure 1). For delayed judgments, they found a U-shaped function, whereas for immediate judgments, they found an inverted-U-shaped function. This pattern was consistent across the two experiments. In delayed JOLs, the presence or absence of the actual retrieval item is a good indicator of future recall. Thus, subjects tend to be highly confident when they do recall, and lack confidence when they do not. However, in immediate judgments, subjects cannot distinguish between retrieval of the just-studied item and its recent activation from the study trial. The subjects reflect this uncertainty by increasing the number of judgments in the middle of the scale (Dunlosky \& Nelson, 1994).

Cue familiarity. Begg et al. (1989) suspected that subjects may also use the ease of processing (or familiarity) of the cue and the target to form cue-only JOLs. Thus, in their Experiment 3, they looked at the effect of abstract and concrete nouns when used as either cues or targets. Target-based hypotheses suggest that the judgments will be higher when the target is more memorable (when the targets are concrete words). Cue-based hypotheses suggest that the JOLs will be higher when the cues are more concrete. Begg et al. (1989) found that both influenced cue-only JOLs. Concreteness of both the cues and the targets increased the magnitude of the JOLs relative to more abstract cues and targets. Thus, whereas Begg et al. (1989) continued to find evidence to support target-based views, the cue concreteness effect suggests that cue-based sources also influence the judgments.

Thus, there is evidence that subjects use target-based sources, such as the products of retrieval, for cue-only JOLs (Begg et al., 1989; Dunlosky \& Nelson, 1994; Narens et al., 1994). Some data support a role for cue-based information (Begg et al., 1989), whereas other data do not (Narens et al., 1994). There is little research that directly addresses the sources used for cue-target JOLs. It is pos-

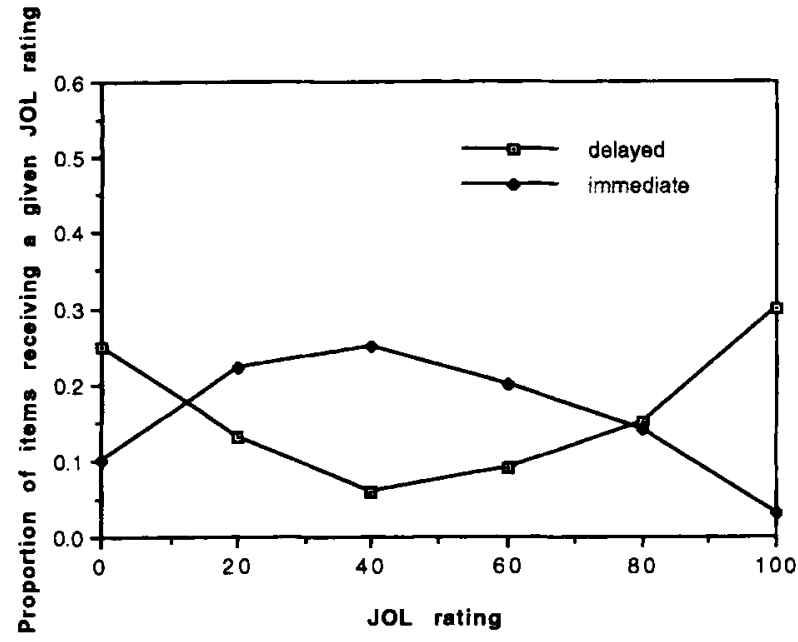

Figure 1. The mean of the proportion of pairs that received a JOL (judgment of learning) rating, showing that the distribution of JOL ratings varies as a function of whether the cue-only JOLs are immediate or delayed. From "Does the Sensitivity of Judgments of Learning (JOLs) to the Effects of Various Study Activities Depend on When the JOLs occur? by J. Dunlosky and T. O. Nelson, 1994, Journal of Memory \& Language, 33, p. 554. Copyright 1994 by Academic Press. Adapted by permission.

sible that cue-target JOLs will resemble the immediate cue-only JOLs of Dunlosky and Nelson (1992), but this remains speculative. Delineation of this issue represents a challenge in the study of metamemory.

\section{Ease-of-Recognition Judgments}

In an ease-of-recognition judgment, subjects make predictions of the likelihood of their success on a later old/new recognition test. Typically, they see a list of words and make judgments concerning their later ability to recognize these words as old or new. Like judgments of learning, ease-of-recognition judgments are made at acquisition, and they concern future memorability. However, the criterion task is recognition, not recall, and it is done on single items rather than on cuetarget pairs.

Begg, Vinski, Frankovich, and Holgate (1991) looked at ease-of-recognition judgments in a generation task. Subjects were presented with single words, which were either complete (read condition) or had some letters missing (generate condition). They were asked to rate their confidence in future old/new recognition of those words. After study and judgments, the subjects were given a recognition test. Begg et al. (1991) found that the subjects gave higher judgments to generated words than they did to read words. However, they recognized and freely recalled the read and generated words equally. Thus, although these data are suggestive of a targetstrength component to ease-of-recognition judgments, they are not conclusive, because they failed to show a generation effect in the final test (cf. Schwartz \& Metcalfe, 1992). 
Begg et al. (1989) looked at ease-of-recognition judgments as well as paired-associate JOLs. In their first experiment, subjects gave ease-of-recognition judgments for a later old/new recognition test. In a complicated design in which several variables were manipulated, the relevant variables were imagery and word frequency. The subjects studied a list of words that varied in imageability and frequency of use in the English language. During study, some subjects made predictions of future recognition performance (and others judged ease of studying).

Begg et al. (1989) had a simple but innovative hypothesis. They suggested that subjects use the ease or speed of their own processing of the targets as a source of information when making ease-of-recognition judgments. They suspected that high-imagery words would lead to high magnitude and better recognition performance than would low-imagery words. Applying the same logic, Begg et al. (1989) suspected that common (high-frequency) words, which are processed more quickly, would be given higher ease-of-recognition judgments than would uncommon words. Actual recognition, however, would be better for the low-frequency words. This is exactly the pattern that Begg et al. (1989) found (see Table 2). Recognition was high for high-imagery words and low-frequency words, but judgments were high for high-imagery and high-frequency words. Begg et al. (1989) interpreted this as being consistent with the ease-of-processing hypothesis.

Although it is similar to other target-based views, the ease-of-processing account differs in the proposed basis by which judgments are made. First, rather than suggesting that metamnemonic judgments are a function of the strength of a memory representation or the amount of partial information retrieved, the ease-of-processing view proposes that fluent processing of presented information results in stronger judgments. In that sense, it is similar to the cue familiarity hypothesis for feelings of knowing. Second, the ease-of-processing and directaccess hypotheses suggest different outcomes for the ease-of-recognition judgment experiment described previously. A direct-access target view would suggest that low-frequency words, because they will be better recognized, should show higher judgments. However, the

Table 2

Mean Ease-of-Recognition (EOR) Judgments and Recognition Scores as a Function of Imagery and Word Frequency in Begg et al. (1989)

\begin{tabular}{lccccccc}
\hline & \multicolumn{3}{c}{ Imagery } & & \multicolumn{3}{c}{ Frequency } \\
\cline { 2 - 4 } \cline { 6 - 8 } & High & Medium & Low & & High & Medium & Low \\
\hline Recognition & 3.51 & 2.91 & 2.09 & & 2.34 & 2.82 & 3.36 \\
EOR judgment & 4.58 & 4.12 & 3.85 & & 4.69 & 4.18 & 3.68 \\
\hline
\end{tabular}

Note-Recognition scores are defined as the differences in scores of hits (saying "old" on old items) and false alarms (saying "old" on new items). From "Memory Predictions are Based on Ease of Processing," by 1. Begg, S. Duft, P. Lalonde, R. Melnick, and J. Sanvito, 1989, Journal of Memory \& Language, 28, pp. 614-615. Copyright 1989 by Academic Press. Reprinted by permission. ease-of-processing view advances that high-frequency words, because they are processed more fluently, will receive higher judgments. As discussed above, the data support the ease-of-processing view. Begg et al.'s (1989) data are not inconsistent with Koriat's (1993) theory that subjects rely on the retrieval of information and the fluency of that retrieval. Thus, the present results are also consistent with the fluency aspect of Koriat's accessibility heuristic theory.

The relation between sources may also be important. First, the sources need not be independent of each other. For example, a familiar cue may induce a subject to "search" memory more thoroughly. This search may result in the retrieval of partial information (e.g., Koriat, 1993). Under ordinary circumstances, cue familiarity and the retrieval of partial information may be correlated. Similarly, in ease-of-recognition judgments, cue familiarity and ease of processing of the target are identical; subjects make judgments of later target recognition in the presence of the actual target. Thus, the cue (item being judged now) and the target (item to be recognized later) are identical. These two sources are separable only in tasks in which subjects make judgments for targets that are not present. Then, the familiarity or ease of processing of the cue can be compared with the ease of retrieving target information.

\section{Free-Recall Judgments of Learning}

A JOL that has appeared under various labels is one that predicts future free recall. These judgments have alternatively been called memorability ratings (Mazzoni et al., 1990), judgments of learning (Mazzoni \& Cornoldi, 1993; Nelson, 1993), the "feeling-that-I-willknow" phenomenon (Groninger, 1979), and free-recall predictions (Schwartz \& Bjork, 1993). These judgments will be referred to here as free-recall JOLs to distinguish them from judgments of cued performance. In a freerecall JOL, a subject assesses a single target item for the likelihood of later free recall. Outwardly, it appears similar to ease-of-recognition judgments, but, as will be discussed shortly, it appears to be based on different sources.

Groninger (1979) examined the accuracy of freerecall JOLs. He gave subjects a list of common words and asked them to predict the likelihood of later free recall. He varied word frequency and imageability of the words. He found that free-recall predictions were above chance in predicting free-recall performance, although his subjects were overconfident and far from perfect. In addition, frequency and imageability were both positively correlated with the free-recall predictions. Mazzoni et al. (1990) used a similar procedure (Experiments 1 and 2) and found (1) above-chance predictions, and (2) a correlation between those predictions and later allocation of study time (this has implications for theories of metacognitive control; see Nelson \& Narens, 1990).

Schwartz and Bjork (1993) examined the sources of information that subjects use in determining these judg- 
ments. They initially suspected that, like the ease-ofrecognition judgments, the subjects would use ease of processing as a source for the judgments. Following Begg et al. (1989), they also suspected that the ease of processing would be used even when it did not lead to accurate predictions. Thus, they hypothesized that, under certain circumstances, the correlation between free-recall JOLs and free-recall performance would be negative. To test this idea, they examined the relation between cued recall and free recall (Gardiner, Craik, \& Bleasdale, 1973). Subjects first answered a series of general-information questions. After answering each question, they predicted the likelihood of freely recalling the answer to each question. Then, either $5 \mathrm{~min}$ or $48 \mathrm{~h}$ later, they were given the free-recall task. Schwartz and Bjork replicated Gardiner et al.'s results: The items that were difficult to retrieve initially (longer than $15 \mathrm{sec}$ ) were more likely to be freely recalled.

Schwartz and Bjork (1993) assumed that the initial retrieval latency is positively related to the ease of processing the initial question. They suspected that subjects would misattribute ease of processing the question to later ease of generating the target in free recall. The data did not support this idea, however. First, the subjects' predicttions of free recall were better than chance (gamma correlation $=.40$ ). If they had based their judgments on ease of processing, lower-than-chance predictions would have resulted. Second, there was a slight positive relation between initial latency and free recall (gamma correlation $=.09$ ). Thus, the subjects may have attributed the initial difficulty to later ease. Schwartz and Bjork speculated that, under these conditions, subjects may correctly rely on episodic distinctiveness.

\section{Feelings of Knowing: Retrieval Judgments}

A second type of metamnemonic judgment is made at the time of retrieval (Nelson \& Narens, 1990). When subjects try to retrieve an item, they may utilize processes in assessing future performance that are different from those used for encoding. The process of making a prospective judgment at the time of retrieval will be called feeling of knowing. This will allow generalizations across divers judgments made at retrieval. As will become apparent, feelings of knowing may operate according to similar processes across different tasks. Three major feelings of knowing will be considered-speeded retrieval decisions that are made immediately prior to an attempted retrieval (Reder, 1987; Reder \& Ritter, 1992), tip-of-the-tongue states that are made immediately following an attempted retrieval (R. Brown $\&$ McNeill, 1966), and feeling-of-knowing judgments that are also made following retrieval (Hart, 1965).

\section{Speeded Strategy Decisions}

Reder $(1987,1988)$ introduced a new technique to assess metamemory at the time of retrieval. In Reder's "game show" technique, subjects determine future memorability of an item that has not been recalled. The judgment immediately precedes the retrieval, and it is accomplished under speeded conditions. The technique allows assessment of the feeling of knowing on all items, not simply on unrecalled ones (see Miner \& Reder, 1994). This offers a methodological advantage over the "classic" feeling-of-knowing measures (see discussion of item selection in Miner \& Reder, 1994; Narens et al., 1994; Schwartz \& Metcalfe, 1992, 1994). The speeded strategy decision technique avoids item selection, because subjects make judgments on all items.

In the game show paradigm, subjects make speeded decisions about whether they can recall the answer to a question (Reder, 1987, 1988). The materials used were general-information questions, such as "What river flows through the city of Paris?" One group of subjects said "yes" when they retrieved the correct answer, and a second group said "yes" when they thought that they would be able to retrieve the answer (hence, a feeling of knowing). After making these decisions, the subjects attempted to retrieve the correct answers. They were able to make these speeded "will know" judgments and, indeed, made them faster, on average, than the "do know" judgments, without a cost in accuracy. Reder (1987) argued that the subjects must have used information other than the target to make these judgments, because they made the decisions prior to retrieval. Indeed, Reder (1987) suggested that they must have based the feeling of knowing, as revealed by the "will know" judgments, on information in the question or the cue. Thus, Reder (1987), like Koriat and Lieblich (1977), hypothesized that cue-based information may be important in determining feeling of knowing.

Unlike earlier, correlational work (Koriat \& Lieblich, 1977; Schacter, 1981), Reder (1987, 1988) examined experimentally the influence of cue familiarity on questionanswering strategies. She primed words in the question prior to the judgments to induce higher cue familiarity. The words chosen as primes were the two words considered most important in the question. For example, for the question "What is the term in golf for scoring one under par?", golf and par were primed. The subjects made frequency judgments on these words by indicating how often the words were encountered while reading. Then, they quickly decided whether they knew the answer to a general-information question. The primed items were judged as answerable by the subjects more than were the unprimed items, but only for the difficult items. Thus, cue priming led directly to a "spurious" increase in feeling of knowing for difficult items.

In the second task (Reder \& Ritter, 1992), the subjects made speeded strategy-selection decisions with arithmetic problems. They were presented with a series of arithmetic problems, such as $14 \times 34$. The subjects engaged in mental arithmetic operations such as multiplication and addition (Experiment 1), or multiplication and a newly learned arithmetic operation, called sharp (Experiment 2). The subjects' first task was to decide whether they could retrieve the answer to the arithmetic problem from memory or whether they needed to cal- 
culate it mentally. They were required to produce the answer within a temporal deadline. If a subject chose "retrieve" (assumed to reflect a high feeling of knowing), $1 \mathrm{sec}$ was allowed to produce the answer. If "calculate" (low feeling of knowing) was chosen, $18 \mathrm{sec}$ were allotted. For example, if the arithmetic problem $14 \times 34$ was presented, the subjects were required to indicate whether they should "retrieve" or "calculate." Incentives were given to promote choosing the "retrieve" strategy. Following this decision, they were to produce the correct answer (476) within either time framework.

In an initial training session, Reder and Ritter (1992) varied the frequency with which the subjects saw multiplication or addition (or sharp in Experiment 2), the frequency with which they saw particular operands, and the frequency with which given pairs of operands occurred together. Thus, for 1 subject, one problem $(14 \times 34)$ may have occurred 20 times, another problem $(14 \times 23)$ may have occurred 8 times, and a third problem $(21+17)$ may have occurred only once. Furthermore, they presented a posttraining set that included problems that were identical to studied ones, problems with the operands reversed (e.g., $14 \times 34$ became $34 \times 14$ ), and new problems, consisting of the same number that had been used in the training set, but with the operator switched $(21+17$ became $21 \times 17)$. This design allowed Reder and Ritter to look at strategy selection as a function of the frequency of the stimulus (number of times two numbers were paired in a question) and the frequency with which they were exposed to the answer (by looking at the switched-operator problems).

Reder and Ritter (1992) were interested in whether subjects choose to calculate an answer mentally, or retrieve the answer from memory after repeated testing. The first critical manipulation was that some of the problems were seen many times throughout the experiment, whereas others were shown only occasionally. The second critical manipulation was the inclusion of the reversed-operator problems in the posttraining set. These were questions that would appear familiar, but for which the answer would not have been calculated or retrieved previously. Reder and Ritter found that, as the frequency of exposure increased, the subjects became more likely to choose the "retrieve" strategy, indicating an increased feeling of knowing for those items. However, Reder and Ritter (1992) also found that, for the reversed-operator problems, the subjects became more likely to choose "retrieve" as a function of increased exposure to the problem parts, even though they had not been exposed to the answer. Thus, Reder and Ritter concluded that the subjects' strategy choice was based on an assessment of cue familiarity, and not on an "early read of the answer."

Reder and Ritter (1992) argued that it is important to distinguish between the feeling-of-knowing process and the retrieval process. The latter process is controlled, requires mental energy, and may vary in the amount of time required to complete it. Feeling of knowing, however, is quick and automatic (see Metcalfe, 1993, for a similar view). Reder and Ritter argued that people use the output of this automatic preretrieval process to judge feeling of knowing. This process is nonanalytic and inferential. In this sense, they argue that cue familiarity is a heuristic used to determine feelings of knowing. When cue familiarity correlates with target availability, the decision to calculate or retrieve will be accurate. However, when this correlation is removed (as in Reder and Ritter's operator reversals), the heuristic will lead to errors, and accuracy will decrease.

\section{Tip-of-the-Tongue States}

R. Brown and McNeill (1966) introduced a technique that is now common among researchers for studying tipof-the-tongue (TOT) states. In their experiment, an experimenter read definitions of low-frequency words (e.g., caduceus, zither). If the subjects could not recall a word that matched the read definition, they indicated whether or not they were in a TOT state. The instructions for defining a TOT state in this study were as follows: "If you are unable to think of the word but feel sure that you know it and that you feel sure that it is on the verge of coming back to you then you are in a TOT state" (p. 327). If the subjects were in a TOT state, they often reported partial information, such as first letter, number of syllables, words that sounded similar, or words that meant the same thing. Finally, the subjects were provided with the correct answer and were asked whether the correct word was the word they thought they were seeking.

TOT states and feeling-of-knowing judgments differ in the operational definitions given to subjects (A. S. Brown, 1991). Feeling-of-knowing judgments generally assess whether the subject thinks that he or she will recognize the item, whereas TOT states indicate the subjective feeling that recall is imminent. This procedural difference has led to different emphases in the research. Feeling-of-knowing researchers are concerned with the accuracy of the judgments and the sources underlying them. In contrast, TOT researchers (Burke et al., 1991; Jones, 1989; A. S. Meyer \& Bock, 1992; Ryan, Petty, \& Wenzlaff, 1982) have sought to use the TOT state as a "window" into word retrieval. The argument is that the TOT state may be indicative of a broken, aborted, or slowed retrieval process. By studying retrieval while subjects are experiencing TOTs, "slow-motion photography" of the word retrieval can be obtained (A. S. Brown, 1991). Only recently have researchers begun to explore the processes underlying the experience of TOTs, which is different from using the TOT state as a tool to study retrieval (e.g., Koriat \& Lieblich, 1977; Metcalfe et al., 1993; Smith, 1994).

TOT states and feeling-of-knowing judgments are frequently construed as being two measures of the same underlying process; indeed, generalizations are often drawn from one to the other (Koriat \& Lieblich, 1977; Reder \& Ritter, 1992; Yaniv \& D. E. Meyer, 1987). When Metcalfe et al. (1993) measured both measures in the same experiment, they found that (1) the same vari- 
ables (interference conditions) affected each in the same way, and (2) there was a high correlation between the two. Because the tasks explicitly ask different questions of the subject (prediction of later recognition vs. imminent recall), they are considered separately here. Indeed, some new data now suggest that at least one variable may affect the two judgments in different ways. Widner and Smith (1993) compared high- and low-stress conditions when eliciting both feeling-of-knowing judgments and TOT states. They found that more TOTs were reported under high-stress conditions than under low-stress conditions, but that feeling-of-knowing judgments did not vary as a function of stress. This dissociation suggests that the processes underlying feeling-of-knowing judgments and TOT states may differ in some respects. However, as will become apparent, many similarities do exist.

Products of retrieval. Research has demonstrated a strong correlation between the retrieval of partial information and feeling of knowing (and TOT states). R. Brown and McNeill (1966) showed that subjects who reported that they were in a TOT state were able to correctly produce the first letter of the target and the correct number of syllables at better-than-chance rates. Koriat and Lieblich (1974) followed a similar procedure, but they also asked subjects to produce partial information on questions for which the subjects did not report a TOT state. They found that the subjects could report the first letter better when they were in a TOT state $(71 \%)$ than when they were not $(10 \%)$. Similarly, subjects reported the correct number of syllables more often when they were in TOT states than when they were not. The data support the notion that a TOT state may accompany retrieved partial information (see A. S. Brown, 1991), but they do not show that partial information causes TOT states. These data are suggestive of a products-ofretrieval view, but they do not directly test Koriat's accessibility heuristic for two reasons. First, as just discussed, the data are correlational. Second, Koriat (1993) argued that the retrieval of incorrect information can just as easily lead to a TOT state.

Blocking. A second approach to target-based sources is known as the blocking hypothesis (A. S. Brown, 1991; Koriat, 1994; Metcalfe et al., 1993; A. S. Meyer \& Bock, 1992; Reason \& Lucas, 1984; Roediger, 1974). This hypothesis is sometimes called the "ugly stepsister hypothesis," because of an analogy to the fairy tale "Cinderella" (Reason \& Lucas, 1984). This account states that incorrect information interferes with retrieving the correct answer, but that the inhibited presence of the correct response induces the TOT state (or feeling of knowing). The intruder is retrieved at a conscious level, and is then recognized as incorrect, but continues to interfere with the retrieval of the correct item. The hypothesis concerns an intruder's effect on unretrieved information, and, consequently, the blocking hypothesis is specific to feeling of knowing and TOT states. A. S. Brown wrote that "the blocking perspective suggests that the TOT [tip-of-the-tongue state] represents a memory search that has become sidetracked" (p. 215). The incorrect in- truders have been labeled as blockers (Reason \& Lucas, 1984), interlopers (Jones, 1989; Jones \& Langford, 1987), and related words (A. S. Brown, 1991). The hypothesis suggests that variables that increase the retrieval of these blockers will inhibit correct recall and promote TOT states.

The blocking hypothesis has been tested by presenting subjects with word definitions, along with words that may be phonologically related, semantically related, or related in both ways to the target word. The expectation is that the related word will act as a blocker and will interfere with retrieval, but will increase the production of TOTs. Jones (1989) presented subjects with the definitions of difficult words and asked them to retrieve the target word. For some of the items (e.g., sextant), he presented a word that was semantically related (e.g., compass) to the target word along with the definition. For other items, he presented a word that was phonologically related (secant). He hypothesized that if blocking was crucial to TOT states, then presenting a potential blocker should increase the likelihood that a subject would report a TOT state. His results were mixed: semantic blockers did not increase the likelihood of a TOT state, but phonological blockers did. A. S. Meyer and Bock (1992) used this technique and replicated Jones by using the same stimuli, but found that Jones's results may have been due to idiosyncratic characteristics of the materials used. In a second experiment, A. S. Meyer and Bock used a greater range of word frequency and found that neither semantic nor phonological blocking affected the rate of TOTs. A. S. Meyer and Bock also found that the condition that led to the highest reported TOT levels in Jones-- the phonological cuing condition-actually led to the highest number of correct responses, but there were no differences in the number of reported TOTs. It is unclear how the null effect on TOTs should be interpreted, however, because A. S. Meyer and Bock did not control for item-selection effects.

Smith and his colleagues (Smith, 1994; Smith, J. M. Brown, \& Balfour, 1991) have designed a useful set of stimuli for studying the TOT phenomenon. Subjects are presented with a series of fictional animals. They see a picture of the animal, a description of its temperament, habitat, and food preferences, and a randomly chosen name. The subjects study these fictional animals (TOTimals) to varying degrees. At some point later, they are shown the picture of the animal, and they try to recall its name. If they are unable to do so, they are asked whether they are in a TOT state. Smith et al.'s first study demonstrated that TOTs generated in this paradigm were not subjectively different from those elicited with more traditional methods. Thus, Smith's technique maintains the experimental control that the word pairs afford, and it generates the ecological validity that the word definitions allow.

Smith (1994) reported an experiment that was designed to examine the blocking hypothesis as well as what Smith called the incomplete activation hypothesis, a version of the direct-access view. Smith had subjects 
learn the names of fictional animals. Later, at test, they were presented with the picture of the animal, along with a word that was phonologically similar to the name (bantergin when the animal's name was boshertin), the name of another animal (rittlefin), or a word that was unrelated to the target name. Smith found that recall for the phonologically similar items was better than that for control items, and that there was no increase in the reported number of TOT states. However, the semantically similar cues (i.e., other animal names) increased recall as well as TOT states. Thus, semantically similar items were likely to induce TOT states. This pattern of results is consistent with the blocking hypothesis; the semantically similar items caused the subjects to think the items were recallable. It is not clear, however, whether this was the result of true blocking of target retrieval with misleading information, or whether the semantically similar items served as partial information about the target, thus raising the likelihood of a TOT state.

Cue familiarity. Because of the availability of partial information and the strong subjective experience associated with TOT, most theorists have ignored the possibility of cue-based sources in the TOT state. However, some data support the hypothesis that cue familiarity does influence TOT states. Indeed, only two studies have addressed this issue, but both point toward a possible role for the use of cue information in determining TOT states.

Koriat and Lieblich (1977) reanalyzed their earlier data (Koriat \& Lieblich, 1974) to examine the relation between reported TOTs and the questions (pointers) that elicited the TOTs. Although Koriat and Lieblich (1977) analyzed the pointers along several dimensions, the most relevant finding for the present paper is that question redundancy led to a greater number of reported TOT states for an unrecalled item than did more succinct definitions. For example, definitions with repetitive elements, such as "a circle, or any indication of radiant light, around the heads of divinities, saints, sovereigns in pictures, medal, etc." (nimbus) tended to produce more TOT states than did more concise definitions, such as "the science of coins" (numismatics). This trend toward more TOTs from questions with repetitive elements also held for TOTs that were resolved (i.e., eventually recalled or recognized) and those that were not. Thus, Koriat and Lieblich's results suggest that cue factors, in addition to target factors, may play a role in forming TOTs.

Metcalfe et al. (1993) directly tested the respective roles of cue-based and target-based sources in TOT states. Subjects studied cue-target word pairs. In one condition, the cue and the target were repeated (A-B $A-B)$. In a second condition, the cue was repeated, but with a new, unrelated target (A-B A-D). In a third condition, neither the cue nor the target was repeated (A-B C-D). In accordance with previous results from interference paradigms, Metcalfe et al. found lowest recall for the A-B A-D condition. Recall was highest in the $\mathrm{A}-\mathrm{B} \mathrm{A}-\mathrm{B}$ condition, presumably because both the cue and the target were repeated. If reported TOTs are based on the strength of the representation, the A-B A-B condition would also show the highest number of TOT states (and the highest magnitude of feeling of knowing). Cue familiarity, however, predicts that because the cue is repeated in both conditions (A-B A-B and A-B A-D), reported TOT states will be higher (and will be the same) in these conditions than in the condition in which the cue is presented only once (A-B C-D). Indeed, Metcalfe et al. found that the repetition condition ( $\mathrm{A}-\mathrm{B} \mathrm{A}-\mathrm{B})$ and the interference condition (A-B A-D) both showed a higher percentage of TOTs than did the once-presented condition. Thus, they found that cue repetition led to more TOT states (and higher feeling-of-knowing judgments), regardless of the level of memorability.

Metcalfe et al. (1993) used randomly selected, experimentally learned word pairs. Furthermore, their subjects were given only one two study opportunities. Although Metcalfe et al. used episodic paired associates, most TOT studies have been done with semantic knowledge, such as word definitions (R. Brown \& McNeill, 1966; Jones, 1989; Koriat \& Lieblich, 1977; A. S. Meyer \& Bock, 1992), famous people (Brennan, Baguley, Bright, \& Bruce, 1990), animal names (Smith, 1994), or trivia questions (Freedman \& Landauer, 1966; Yaniv \& D. E. Meyer, 1987). Given the differences in stimuli and procedures between Metcalfe et al., Jones, A. S. Meyer and Bock, and Smith, it may be erroneous to generalize across such studies. Nonetheless, it appears that target (blocking) and cue (cue familiarity) information may both play a role in determining TOT states. However, the data are still inconclusive, and the sources of information that cause the TOT state are yet to be determined.

\section{Feeling-of-Knowing Judgments}

Hart $(1965,1966,1967 \mathrm{a})$ introduced the RJR (recall/judgment/recognition) technique that is now common in feeling-of-knowing research. The technique is useful for determining possible underlying sources of information and for assessing the accuracy of the judgments. In Hart's experiments, subjects attempted to recall information from a cue, either from generalinformation questions (Hart, 1965) or from the stimulus of experimentally learned word pairs (Hart, 1967a). If they were unable to recall a given item, they made a feeling-of-knowing judgment for that item. Hart's subjects received the following instructions: "If you check the Yes column [positive feeling-of-knowing judgments], that will indicate that you have a feeling that you know the correct answer even though you cannot remember it at the moment. The criterion question to ask yourself before you check the Yes column is 'Even though I cannot remember it now, do I know the answer to the extent that I could pick the answer from among several wrong answers?'” (Hart, 1965, p. 209). After the judgments, the subjects engaged in a recognition test for the unrecalled items. Hart was interested in whether the judgments were predictive of memory performance. He found that people could make accurate predictions of 
recognition for unrecalled items, but that the correlation was far from perfect.

Since Hart's seminal work, much research has focused on feeling of knowing, and other researchers have extended Hart's RJR technique (see Metcalfe \& Shimamura, 1994; Nelson, 1992). Indeed, many researchers have used ordinal or magnitude scales to assess feeling of knowing (Blake, 1973; Nelson et al., 1982; Nelson \& Narens, 1980a; Schacter, 1983; Wellman, 1977) and have substituted other criterion tests for recognition, such as reminiscence (Gruneberg \& Sykes, 1978; Hart, 1967b; Metcalfe et al., 1993), first-letter cued recall (Gruneberg \& Monks, 1974), lexical decision (Connor, Balota, \& Neely, 1992; Yaniv \& D. E. Meyer, 1987), stem completion (Lupker, Harbluk, \& Patrick, 1991), perceptual identification (Nelson et al., 1984), relearning (Nelson et al., 1984), and attribute identification (Koriat, 1993; Schacter \& Worling, 1985).

Feeling-of-knowing judgments tend to be above chance in predicting most criterion tasks (see Nelson, 1988). Accuracy for feeling of knowing tends to be higher (1) for general-information questions than for paired-associate learning (Nelson \& Narens, 1990), (2) for items studied to a higher criterion than for those studied to a lower criterion (Nelson et al., 1982), (3) for items with more alternatives at test than for those with fewer (Schwartz \& Metcalfe, 1994), and (4) for items with a wider range of difficulty than for those with a narrower range (Nelson, Leonesio, Landwehr, \& Narens, 1986; Schwartz \& Metcalfe, 1994). Feeling of knowing also predicts performance in $n$-alternative recognition (Blake, 1973; Hart, 1967a), yes/no recognition (Costermans et al., 1992), first-letter cued recall (Gruneberg \& Monks, 1974), reminiscence (Metcalfe et al., 1993), stem completion (Lupker et al., 1991), and perceptual identification and relearning (Nelson et al., 1984). Although most amnesic patients do show accurate feeling of knowing, patients with Korsakoff's amnesia cannot predict performance (Shimamura \& Squire, 1986). Furthermore, patients with frontal lobe damage show a deficit in feeling-of-knowing accuracy (Janowsky, Shimamura, \& Squire, 1989). The latter two findings suggest that the frontal lobe plays a role in the neuropsychology of metamnemonic judgments (see Metcalfe, 1993, 1994; Shimamura, 1994). In total, the results buttress the claim that subjects do make accurate metamnemonic judgments.

Cue familiarity. The earliest work on cue familiarity with feeling-of-knowing judgments can be found in a doctoral dissertation by Schacter (1981), who asked subjects to study word pairs. He later gave a series of tests, which included recall, feeling of knowing, cue recognition, and target recognition. He specifically asked the subjects to make old/new recognition judgments as well as feeling-of-knowing judgments on words, some of which were cues in a memory task. He found that cue recognition and feeling-of-knowing judgments were positively correlated. However, a causal relation be- tween cue recognition and judgments cannot be drawn from this study.

Schwartz and Metcalfe (1992) directly tested the cue familiarity hypothesis and a target retrievability hypothesis with a Hart-like RJR paradigm. To manipulate cue familiarity, they adapted Reder's (1987) priming technique. In an initial phase, subjects rated a series of words for pleasantness; some of these words would be cues in cue-target learning. The pleasantness judgments served as the cue priming task. The subjects then studied the cue-target pairs and later engaged in a recall task. They indicated feeling of knowing for unrecalled items by assessing their confidence in subsequent recognition. Schwartz and Metcalfe (1992) found that cue priming resulted in an increase in the magnitude of the feelingof-knowing judgments. In addition, Metcalfe et al. (1993) found that cue repetition led to higher feeling of knowing without increasing recall or recognition.

The generation effect has been used to control levels of memorability. Slamecka and Graf (1978) found that subjects' recall for generated pairs was better than that for pairs they had read. This technique required subjects, during study, to generate the target to a cue, following an experimenter-provided rule (rhyming) such as PAILS__ (sail). Other items were read by the subject (MOONNOON). In addition, unrelated pairs (DIVE-FINGER) were studied. Schwartz and Metcalfe (1992) replicated the generation effect for both recall and for subsequent recognition of the unrecalled items. However, feelingof-knowing judgments were not influenced by the generation manipulation. There was no difference in feeling of knowing between the generated, the read, and the unrhymed pairs. Because large differences in memorability were unaccompanied by corresponding changes in feeling-of-knowing judgments, Schwartz and Metcalfe interpreted their results as damaging to the target retrievability hypothesis.

Narens et al. (1994) criticized Schwartz and Metcalfe's (1992) interpretation of the null effects of generation on feeling-of-knowing judgments. Narens et al. pointed out that Schwartz and Metcalfe (1992) examined feeling-of-knowing judgments only for unrecalled items, and that this may have created an item-selection effect. Thus, the sample of unrecalled items may have systematically differed from the sample as a whole (see Schwartz \& Metcalfe, 1994). Narens et al. asked whether Schwartz and Metcalfe's (1992) results would have been different if their subjects had been required to make judgments on all the items. Schwartz and Metcalfe (1992) had discussed the item-selection problem, but dismissed it because the generation effect did increase recognition of the unrecalled items, yet did not affect feeling of knowing for those same items. Narens et al. noted, however, that Schwartz and Metcalfe's (1992) recognition test was flawed as well. Because all of the distractors were new items, the subjects did not have to retrieve the association. Rather, their recognition judgments could have been based on familiarity of the tar- 
get. For this reason, Metcalfe et al. (1993) chose old items as distractors in one experiment and looked at second-try recall in another. Even with these modifications, Metcalfe et al.'s data were inconsistent with the targetstrength account of feeling of knowing, because target repetition increased final test performance of originally unrecalled items without affecting feeling-of-knowing judgments. Nonetheless, the results of Schwartz and Metcalfe (1992) and Metcalfe et al. do support a role for cue familiarity in forming feeling-of-knowing judgments.

Target strength. Hart (1967a) proposed that feeling of knowing was a result of memory strength that was below a hypothetical recall threshold, but above a hypothetical feeling-of-knowing threshold. Although this model may be intuitively plausible, there has been little empirical support for it. For example, Schwartz and Metcalfe (1992) did not find a generation effect in feelingof-knowing judgments. Indeed, there is only one study that supports a target-strength view (Yaniv \& D. E. Meyer, 1987), and the interpretation of this study has recently been criticized (Connor et al., 1992) for not considering an alternative explanation.

Yaniv and D. E. Meyer (1987) were interested in the underlying processes in metamemory. They presented subjects with word definitions, such as "a mythical figure, half-man, half-horse" (centaur). The subjects were required to give TOT judgments and feeling-of-knowing judgments (which Yaniv and D. E. Meyer combined into "latent accessibility" scores) for definitions whose referent they could not recall. They observed that subsequent lexical decisions were faster for unrecalled words given high latent-accessibility scores than for unrecalled words given low latent-accessibility scores. Yaniv and D. E. Meyer interpreted these results as indicating that the word definitions had partially activated the representations of the targets. They concluded that targets with high activation received high feeling-of-knowing judgments, and higher activation caused these targets to be more speedily processed later.

Connor et al. (1992) disputed this interpretation. Their first experiment replicated the results of Yaniv and D. E. Meyer (1987). In a second experiment, however, they reversed the order of the feeling-of-knowing task and the lexical decision task. In this experiment, the lexical decision task occurred 1 week prior to the definitionrecall task and the metamnemonic judgments. In this condition, lexical decisions were still faster for targets that later would be given high latent-accessibility scores. Partial activation of the unrecalled target cannot explain these results, because the lexical decision occurred before the word-definition task.

Jameson, Narens, Goldfarb, and Nelson (1990) also reported findings that are inconsistent with the subthreshold version of target-based information. They were interested in the effects of subliminal priming on feeling-of-knowing judgments. In their priming technique, they presented the correct answer to the subjects tachistosocopically, near the measured threshold of conscious perception. The target was immediately followed by a pattern mask. For example, the subjects may have read the question, "What is the capital of Thailand?" If they could not recall the correct answer, either the name Bangkok or a nonsense prime was briefly presented and then masked. The subjects were then given a feeling-ofknowing task for the unrecalled question. They found that although near-threshold target priming resulted in better recall of general-information questions, it did not affect feeling-of-knowing judgments.

Several studies now suggest that cue familiarity may play a role in feeling-of-knowing judgments (Metcalfe et al., 1993; Schwartz \& Metcalfe, 1992). Furthermore, a number of studies argue against the role of the target itself in the judgments (Connor et al., 1992; Jameson et al., 1990; Metcalfe et al., 1993; Schwartz \& Metcalfe, 1992). Nonetheless, the studies mostly deal with target retrieval in a simplistic, direct-access fashion. Some of the theorists who support target-based views have considered more complex inferential approaches to target sources (Koriat, 1993, 1994; Nelson \& Narens, 1990). In the next section, this inferential approach to target sources in feeling-of-knowing judgments is discussed.

The accessibility heuristic. An elaboration of the products-of-retrieval hypothesis is called the accessibility heuristic hypothesis (Koriat, 1993, 1994), the "no magic" hypothesis (Nelson \& Narens, 1990), or the omnibus retrieval hypothesis (Metcalfe et al., 1993). Koriat argued that feeling-of-knowing judgments are based on any retrieved information, regardless of whether the information is correct or incorrect. He also proposed that the feeling of knowing may also depend on the intensity of the partially retrieved information (see Begg et al., 1989). For instance, if the partial information is particularly vivid, specific, or persistent, the feeling of knowing will be stronger. Koriat's approach, like Nelson and Narens's (1990), does not limit the partial information to correct information. Any retrieved information may be weighted in the judgment. His approach does not assume that the subjects have any special access to the unretrieved item. Rather, Koriat postulates that "monitoring" is "parasitic" on the retrieval process. If the partial information retrieved happens to be correct, the feelingof-knowing judgments will predict performance. If incorrect partial information is retrieved, feeling of knowing will be high, but it will not correlate with correct performance.

The data supporting this theory are generally drawn from studies that show a relation between feeling-ofknowing judgments and the amount of partial information recalled by the subjects. For example, Blake's (1973) subjects studied three-letter trigrams (e.g., MKD) and, after an 18-sec distractor task, attempted to recall as many letters as possible from the series. If they could not recall all of the letters, they made feeling-of-knowing judgments and then engaged in a recognition task. Blake discovered that partial recall of the three-letter trigrams was related to higher reported feeling of knowing for those items. In a similar experiment, Koriat (1993) had subjects recall as many letters as they could from four- 
or five-letter strings. They were then asked to give feelingof-knowing ratings for future recognition. The more letters a subject produced, the higher the feeling of knowing. Blake's and Koriat's tasks differed from the standard RJR paradigm in one important respect-no explicit cues were given. The to-be-recalled information was the letter sequence the subject had just seen, and the task was to free recall the letters. Thus, unlike other feelingof-knowing tasks, the subjects could not rely on cue familiarity to make their judgments. Because the task involved free recall, they must have relied on alternative sources of information. Thus, it may become necessary to distinguish this task from the standard RJR task.

Krinsky and Nelson's (1985) data are also relevant to the accessibility heuristic approach. They were interested in whether feeling of knowing following a commission error (an incorrect response) was different from feeling of knowing after an omission error (a "do not know" response). The subjects engaged in a standard RJR procedure with general-information questions as stimuli. The experimenters classified each recall error as either a commission or an omission error, depending on the response given. The subjects then made feeling-ofknowing judgments. Krinsky and Nelson found that the subjects gave higher feeling-of-knowing judgments to commission errors than to omission errors. Koriat (1993) interpreted this finding as support for the accessibility heuristic hypothesis, because the recall of incorrect information was correlated with a higher magnitude of the feeling of knowing. Again, however, although Krinsky and Nelson's data are suggestive of a partial-information effect in feeling of knowing, they are correlational.

Schacter and Worling (1985) examined how attribute information of targets influences judgments. Using a standard RJR procedure, they asked subjects to study word pairs. All of the targets were either positive-affect terms (e.g., terrific) or negative-affect terms (e.g., horrible). For unrecalled items, the subjects predicted their feeling of knowing and tried to identify the target as "good" or "bad." They could recall the affective valence of unrecalled items better for items given high feelingof-knowing judgments than for those given lower judgments. These results suggest that partial information may frequently accompany high feeling of knowing. Once again, the availability of target information was not manipulated in these experiments, so caution must be maintained in interpreting this correlational study.

Metcalfe et al. (1993; Experiment 4) looked at reminiscence (recall of previously unrecalled items) after feeling-of-knowing judgments. They found that reminiscence and initial recall were influenced by the same variable; that is, repetition of the target improved memory (A-B A-B > A-D A-B), whereas the feeling-ofknowing judgments were affected by cue repetition (A-B A-B = A-B A-D). However, when they looked at all retrieved information, not simply correct information, they found that the interference condition, $\mathrm{A}-\mathrm{B}$ $\mathrm{A}-\mathrm{D}$, resulted in as many total responses, correct and incorrect, as did the A-B A-B condition. The control con- dition, A-B C-D, showed fewer responses and lower judgments. Metcalfe et al. noted that this result is consistent with Koriat's approach, although they endorsed another interpretation. The combination of the correlational data outlined above and the results of Metcalfe et al.'s experiment suggests that subjects may indeed use retrieved information, when it is available, to inform their feeling-of-knowing judgments.

Domain familiarity. Domain familiarity is an extension of cue familiarity when it is applied to more naturalistic stimuli. Cue familiarity appears to be a source of information in situations in which subjects do not have recourse to target-based information. Indeed, with speeded decisions (Reder, 1987; Reder \& Ritter, 1992), subjects use their feelings of knowing before they can retrieve any information. Furthermore, when impoverished stimuli are used, there may be no partial information for subjects to draw upon, and they may then be left with cue familiarity as the only source of information (Metcalfe et al., 1993; Schwartz \& Metcalfe, 1992). If these subjects cannot recall the target, they may not have access to any partial or related information, because the stimuli are paired associates. However, when more naturalistic stimuli are used, such as general-information questions (Nelson \& Narens, 1980b), subjects may have additional sources of information available, such as related information or memories for prior exposures to the material. It is a matter of semantics to label this related information as target information (the subject must retrieve it) or cue information. Thus, for naturalistic stimuli, the boundaries between cue familiarity and the accessibility heuristic break down. The retrieval of related information, or memory for prior history with the question, may serve as cues for retrieval and additional cues for determining cue familiarity. This hypothesis will be considered here as domain familiarity. Presently, there is no research that addresses the issue of whether domain effects result from cue-based or retrieval-based sources.

The domain familiarity hypothesis states that metamnemonic judgments (usually feeling of knowing) are based on a person's subjective assessment of knowledge about the topic of inquiry (Connor et al., 1992; Costermans et al., 1992; Glenberg et al., 1987; Nelson et al., 1984; Reder, 1988). Nelson et al. (1984) included actuarial information and presumed expertise in this category. According to this hypothesis, if the question falls in a subject's domain of expertise, the judgments will be higher than those in a domain for which the subject reports less knowledge. Like cue familiarity, the judgments are not based on partial information of the specific response. Rather, they arise from an assessment of cue familiarity, except that the whole domain of inquiry may be included as the cue. In this way, the domain familiarity hypothesis mirrors the cue familiarity hypothesis, except that it takes into account a subject's preexperimental experience with tested items.

The domain familiarity hypothesis shares some features with target-based hypotheses as well. According to both views, retrieved information may play a role in the 
judgments. Subjects may rely on the retrieval of domainspecific knowledge to inform their judgments. For instance, if subjects are given a question such as, "What is the capital of Jamaica?", the domain familiarity hypothesis suggests that subjects' feeling-of-knowing judgments are based on related information, such as the major cities of Jamaica, a recent winter vacation to Jamaica, or reggae bands from Jamaica. The critical difference between domain familiarity and target-based information is that, according to the domain familiarity hypothesis, the retrieved information is not restricted to information about the specific target. Rather, related information may increase the familiarity of the domain and cause judgments to change (for a related view, see Nelson et al., 1984; Nelson \& Narens, 1990).

Reder (1988) reported an unpublished experiment that is relevant to the domain familiarity hypothesis. She asked subjects to rank order their knowledge of four topics. The subjects then indicated, as rapidly as possible, whether they knew the answer to a general-information question that was drawn from one of these four topics. The subjects indicated that they were more likely to retrieve an answer for the self-rated familiar topics than for the self-rated unfamiliar topics. The bias to indicate potential knowledge in a highly familiar domain is consistent with the domain familiarity hypothesis (see Miner \& Reder, 1994).

Costermans et al. (1992) were also interested in the effects of domain knowledge on feeling of knowing. Their subjects made feeling-of-knowing judgments for unrecalled general-information questions and then answered a "subsidiary questionnaire." The questions that addressed subjective domain familiarity were "Is the domain of the question familiar to you?" and "How many people around you do you think know the answer to this question?" They found a high correlation (.49 and .63, respectively) between the two questions and subjects' feeling-of-knowing judgments. Costermans et al. interpret these correlational results as being consistent with a domain familiarity account. Further study requires the manipulation of independent variables, such as controlling a subject's knowledge in a given domain.

\section{THE HEURISTIC NATURE OF METAMNEMONIC JUDGMENTS}

Koriat (1993) distinguished between three potential motivations for the study of metamnemonic judgments. First, researchers may study the underlying sources, processes, or mechanisms of the judgments. Second, they may wish to investigate whether or not the judgments predict subsequent performance. Third, they may seek to understand the relation between mechanism and accuracy. Initially, most research focused on the issue of accuracy (Blake, 1973; Groninger, 1979; Hart, 1965; Nelson, 1988; Nelson et al., 1982; Schacter, 1983). More recently, attention has turned to mechanism (Koriat, 1993; Metcalfe, 1993; Reder, 1987, 1988; Reder \&
Ritter, 1992). The relation between the source of judgments and subsequent accuracy has not been systematically investigated. Nonetheless, there have been attempts to explain this relation (Begg et al., 1989; Hart, 1967a; Koriat, 1993; Metcalfe et al., 1993). ${ }^{1}$

In the case of direct access, the relation between judgment and accuracy is straightforward. Because people directly monitor the strength of the memory trace, the metamnemonic judgments should be highly accurate. For example, Hart's (1967a) subthreshold model (see Figure 2) is based on the idea that the feeling of knowing monitors memory strength of items below the threshold of recall. According to this account, feeling-of-knowing judgments should be above chance-indeed, nearly perfect. Hart observed only modest effects and was surprised that the judgments were not more accurate. He speculated that the final test is important in determining accuracy. In his model, the recognition threshold varies as a function of test difficulty. Even if an item has some representation in memory, a difficult (or easy) recognition test may obscure the expression of that memory by allowing recognition to be at ceiling or at floor. Under normal circumstances, however, the judgments will be above chance because the subject's feeling-of-knowing judgments have access to items in memory.

Koriat's (1993) approach centers on the evaluation of partial information rather than on a special monitoring system that "knows" the correct response. The subject must infer whether he or she will retrieve the answer on the basis of the amount of partial information that is available. If enough partial information is retrieved, and if it is of sufficient intensity, the subject will give a positive feeling-of-knowing judgment. Koriat accounts for accuracy by suggesting that subjects tend to retrieve more correct than incorrect information. If more correct information is retrieved, the feeling-of-knowing judgments will tend to be accurate in predicting feeling of knowing. If, however, more incorrect information is retrieved, the feeling-of-knowing judgments may actually be inaccurate.

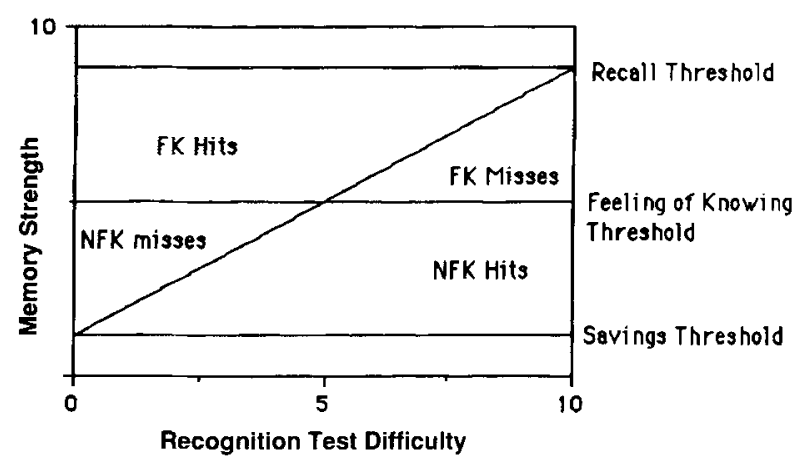

Figure 2. Hart's model of feeling of knowing. FK Hits denotes positive feeling-of-knowing judgments followed by correct recognition. NFK Hits denotes negative feeling-of-knowing judgments followed by incorrect recognition. The diagonal line represents the recognition threshold. 
Koriat's argument is easily extended to cue-only JOLs. Subjects can use retrieved information as a predictor of later recall. If a subject is able to recall the target at the time of making the JOL, this may serve as a good indicator that recall will occur at a later time (Dunlosky \& Nelson, 1992; Nelson \& Dunlosky, 1991). In fact, Spellman and Bjork (1992) note that retrieval may often serve to strengthen the memory involved, and that cue-only JOLs may be a "self-fulfilling prophecy." If an item is retrieved, it not only receives a high judgment, but the act of participating in the judgment task also increases the likelihood of recalling the correctly retrieved items. An implication of this notion is that accurate predictions should lead to better recall performance later. Nelson and Dunlosky (1992), however, noted that recall following immediate JOLs (low accuracy) did not differ from recall following delayed JOLs (high accuracy). Begg, Martin, and Needham (1993) found that the act of making a metamnemonic judgment on a particular item did not raise its likelihood of later recall above the level that would have occurred from an extra study trial. Thus, although JOLs may not offer any benefit over study, using retrieval at judgment as an index of retrieval at test ought to be a good predictor of performance. Indeed, cue-only JOLs tend to be quite accurate, with gammas often reaching .9 or higher.

Begg et al. (1989) argued that subjects use ease of processing to make metamnemonic judgments (see also Kelley \& Lindsay, 1993). They suggested that subjects use ease of processing as a heuristic in determining future memory performance. Like Koriat's accessibility heuristic, Begg et al. (1989) suggested that when ease of processing is correlated with memory behavior, judgments will be accurate. If ease of processing is not correlated with the memory behavior in a given task, the judgments will not be accurate. In their study, however, accuracy did not differ reliably as a function of ease of processing, so, like the other heuristic ideas, this idea remains speculative.

Reder and Ritter (1992) and Metcalfe et al. (1993) used similar arguments to relate cue familiarity to accuracy. Subjects may use cue familiarity as a heuristic to predict target memory. Under normal circumstances, cue familiarity and target memory are correlated; if a cue item is familiar, the target is more likely to be in memory. To the extent that this correlation is true, feelingof-knowing judgments will be accurate. Here, too, if cue familiarity is not correlated with memorability, the judgments will not be accurate.

Generally, there is some agreement that metamnemonic judgments are made by a heuristic, and not by direct access to the target (Begg et al., 1989; Koriat, 1993; Metcalfe et al., 1993; Reder \& Ritter, 1992). Although the nature of the heuristic is still subject to debate, most researchers think that the judgment process involved in making feeling-of-knowing judgments is nonanalytic. Metcalfe et al. (1993) and Reder and Ritter (1992) have argued that subjects use the familiarity of the cue to make judgments concerning unrecalled information. Koriat (1993) has argued that people rely on partial information that is recalled, regardless of whether such information is correct. Begg et al. (1989) have argued that subjects use ease of processing as a heuristic to determine their metamnemonic state. In each case, the measurement is indirect and is based on the correlation between what is actually measured and what the subject wants to know (i.e., whether he or she will retrieve the correct answer).

This heuristic view of metamemory is similar to the attributional approach to memory that was developed by Jacoby, Kelley, and Dywan (1989). They argued that subjects do not always have direct access to their memory processes. Rather, to infer that something occurred in the past, subjects may often rely on nonconscious attributions that are based on such factors as ease of processing. To support this view, Jacoby, Kelley, and Dywan presented several "memory illusions," which were cases in which subjects misattributed new events as also having occurred in the past, and cases in which memory processes influenced other kinds of judgments. Thus, like the heuristic view outlined here, Jacoby's attributional approach also notes the importance of inferential processes in cognition.

Thus, there are two major explanations of metamnemonic accuracy. In the first, accuracy is a function of a system that actually measures the strength of a memory representation (e.g., Hart, 1967a). By this view, metamnemonic judgments should always be accurate, and deviations from perfect performance should be low. In contrast, the heuristic view, endorsed by most researchers, regardless of their specific theoretical bent with respect to the source involved in producing the judgment, suggests that metamnemonic judgments are accurate only when what they measure is, in fact, correlated with memory behavior.

\section{CONCLUSIONS}

The data suggest that different sources of information may be the basis for different metamnemonic judgments. Cue familiarity appears to be important to feelings of knowing, whereas target information appears to be important to judgments of learning. Furthermore, these sources tend to produce judgments that are above chance in predicting criterion performance. However, despite the rather significant advances that have been made in the investigation of metamnemonic judgments, many questions remain. For instance, the research presented here indicates the sources of information that people use in determining their judgments, but the issue of the development of these metacognitive libraries remains unexplored. How do people learn to apply one source under one set of circumstances (see Eagle, 1967)? Indeed, Nelson and Narens (1994) discuss the idea that monitoring and control may take place at multiple levels within the cognitive system. 
Another important issue that needs to be resolved is the role of conscious and nonconscious processes in metacognition. Sources such as cue familiarity, ease of processing, and the products of retrieval may be largely automatic influences on metamnemonic judgments. Generally however, judgments--metamnemonic ones in particular-are considered to be representative of higher order cognition. If so, can subjects apply conscious strategies to override these automatic feelings? Some researchers suggests that more conscious processes may also play a role in determining these judgments (see Begg et al., 1989; Costermans et al., 1992; Nelson et al., 1984).

\section{REFERENCES}

ARBUCKLE, T. Y., \& CUdDY, L. L. (1969). Discrimination of item strength at time of presentation. Journal of Experimental Psychology, 81, 126-131.

AtKınson, R. C., \& Juola, J. F. (1973). Factors influencing speed and accuracy of word recognition. In S. Kornblum (Ed.), Attention and performance $1 V$. New York: Academic Press.

BegG, I. M., ANAS, A., \& Farinacci, S. (1992). Dissociation of processes in belief: Source recollection, statement familiarity, and the illusion of truth. Journal of Experimental Psychology: General, $121,446-458$

BegG, I., Duft, S., Lalonde, P., Melnick, R., \& Sanvito, J. (1989). Memory predictions are based on ease of processing. Journal of Memory \& Language, 28, 610-632.

Begg, I. M., Martin, L. M., \& Needham, D. R. (1993). Memory monitoring: How useful is self-knowledge about memory? European Journal of Cognitive Psychology, 4, 195-218.

BegG, I., Vinski, E., Frankovich, L., \& Holgate, B. (1991), Generating makes words memorable, but so does effective reading. Memory \& Cognition, 19, 487-497.

BJork, R. A., \& BJork, E. L. (1992). A new theory of disuse and an old theory of stimulation fluctuation. In A. F. Healy, S. M. Kosslyn, \& R. M. Shiffrin (Eds.), From learning processes to cognitive processes: Essays in honor of William $K$. Estes (Vol. 2, pp. 35-67). Hillsdale, NJ: Erlbaum

BLAKE, M. (1973). Prediction of recognition when recall fails: Exploring the feeling-of-knowing phenomenon. Journal of Verbal Learning \& Verbal Behavior, 12, 311- 319.

Brennan, T., Baguley, T., Bright, J., \& Bruce, V. (1990). Resolving semantically induced tip-of-the-tongue states for proper nouns. Memory \& Cognition, 18, 339-347.

Brown, A. S. (1991). A review of the tip-of-the-tongue experience Psychological Bulletin, 109, 204-223.

BRown, R., \& MCNEILL, D. (1966). The "tip of the tongue" phenomenon. Journal of Verbal Learning \& Behavior, 5, 325-337.

Burke, D. M., MacKay, D. G., WorThley, J. S., \& Wade, E. (1991). On the tip of the tongue: What causes word finding failures in young and old adults? Journal of Memory \& Language, 30, 542-579.

Connor, L. T., Balota, D. A., \& Neely, J. H. (1992). On the relation between feeling of knowing and lexical decision: Persistent subthreshold activation or topic familiarity? Journal of Experimental Psychology: Learning, Memory, \& Cognition, 18, 544-554.

Costermans, J., Lories, G., \& AnSAY, C. (1992). Confidence level and feeling of knowing in question answering: The weight of inferential processes. Journal of Experimental Psychology: Learning, Memory, $\&$ Cognition, 18, 142-150.

Dunlosky, J., \& NELSON, T. O. (1992). Importance of the kind of cue for judgments of learning (JOL) and the delayed-JOL effect. Memory \& Cognition, 20, 374-380.

Dunlosky, J., \& Nelson, T. O. (1994). Does the sensitivity of judgments of learning (JOLs) to the effects of various study activities depend on when the JOLs occur? Journal of Memory \& Language, 33, 545-565.

EAGLE, M. N. (1967). The effects of learning strategies upon free recall. American Journal of Psychology, 80, 421-425.
FischHOFF, B. (1975). Hindsight $\neq$ foresight: The effect of outcome knowledge on judgment under uncertainty. Journal of Experimental Psychology: Human Perception \& Performance, 1, 288-299.

Freedman, J. L., \& LaNdAUER, T. K. (1966). Retrieval of long-term memory: "Tip-of-the- tongue" phenomenon. Psychonomic Science, 4, 309-310.

Gardiner, J. M., Craik, F. I. M., \& Bleasdale, F. A. (1973). Retrieval difficulty and subsequent recall. Memory \& Cognition, 1, 213-216.

GARDINER, J. M., \& JAVA, R. I. (1993). Recognising and remembering. In A. F. Collins, S. E. Gathercole, M. A. Conway, \& P. E. Morris (Eds.), Theories of memory (pp. 163-188). Hillsdale, NJ: Erlbaum.

Glenberg, A. M., SAnocki, T., Epstein, W., \& Morris, C. (1987). Enhancing calibration of comprehension. Journal of Experimental Psychology: General, 116, 119-136.

GluCKSBerg, S. M., \& MCCloskey, M. (1981). Decisions about ignorance: Knowing that you don't know. Journal of Experimental Psychology: Human Learning \& Memory, 7, 311-315.

Groninger, L. D. (1979). Predicting recall: The "feeling-that-I-willknow" phenomenon. American Journal of Psychology, 92, 45-58.

GruneberG, M. M., \& MonKs, J. (1974). Feeling of knowing and cued recall. Acta Psychologica, 38, 257-265.

GRUNEBERG, M. M., \& SYKES, R. N. (1978). Knowledge and retention: The feeling of knowing and reminiscence. In M. M. Gruneberg, P. E. Morris, \& R. N. Sykes (Eds.), Practical aspects of memory (pp. 189 196). New York: Academic Press.

HART, J. T. (1965). Memory and the feeling-of-knowing experience. Journal of Educational Psychology, 56, 208-216.

HART, J. T. (1966). A methodological note on feeling-of-knowing experiments. Journal of Educational Psychology, 57, 347-349.

HART, J. T. (1967a). Memory and the memory-monitoring process. Journal of Verbal Learning \& Verbal Behavior, 6, 685-691.

HART, J. T. (1967b). Second-try recall, recognition, and the memorymonitoring process. Journal of Educational Psychology, 58, 193-197.

JACOBY, L. L. (1991). A process dissociation framework: Separating automatic from intentional influences of memory. Journal of Memory \& Language, 30, 513-541.

JACOBY, L. L., \& BROOKS, L. R. (1984). Nonanalytic cognition: Memory, perception, and concept learning. In G. Bower (Ed.), The psychology of learning and motivation: Advances in research and theory (Vol. 18, pp. 1-47). New York: Academic Press.

JACOBY, L. L., \& KELLEY, C. M. (1987). Unconscious influences of memory for a prior event. Personality \& Social Psychology Bulletin, 13, 314-336.

JACOBY, L. L., Kelley, C. M., \& DYWAN, J. (1989). Memory attributions. In H. L. Roediger, III \& F. 1. M. Craik (Eds.), Varieties of memory and consciousness: Essays in honour of Endel Tulving (pp. 391 -422). Hillsdale, NJ: Erlbaum.

JACOBY, L. L., WoloshYN, V., \& Kelley, C. M. (1989). Becoming famous without being recognized: Unconscious influences of memory provided by divided attention. Journal of Experimental Psychology: General, 118, 115-125.

Jameson, K. A., Narens, L., Goldfarb, K., \& Nelson, T. O. (1990). The influence of near-threshold priming on metamemory and recall. Acta Psychologica, 73, 55-68

Janowsky, J. S., Shimamura, A. P., \& SQuire, L. R. (1989), Memory and metamemory: Comparisons between patients with frontal lobe lesions and amnesic patients. Psychobiology, 17, 3-11.

Johnson, M. K., Hashtroudi, S., \& Lindsay, D. S. (1993). Source monitoring. Psychological Bulletin, 114, 3-28.

Johnson, M. K., \& Raye, C. L. (1981). Reality monitoring. Psychological Review, 88, 67-85.

JoNES, G. V. (1989). Back to Woodworth: Role of interlopers in the tipof-the-tongue phenomenon. Memory \& Cognition. 17, 69-76.

Jones, G. V., \& LANGFord, S. (1987). Phonological blocking in the tip of the tongue state. Cognition, 26, 115-122.

Kelley, C. M., \& LindSAY, D. S. (1993). Remembering mistaken for knowing: Ease of retrieval as a basis for confidence in answers to general knowledge questions. Journal of Memory \& Language, 32, $1-24$.

King, J. F., Zechmeister, E. B., \& Shaughnessy, J. J. (1980). Judgments of knowing: The influence of retrieval practice. American Journal of Psychology, 93, 329-343. 
Kolers, P. A., \& Palef, S. R. (1976). Knowing not. Memory \& Cognition, 4, 553-558.

Koriat, A. (1993). How do we know that we know? The accessibility account of the feeling of knowing. Psychological Review, 100,609639

KORIAT, A. (1994). Memory's knowledge of its own knowledge: The accessibility account of the feeling of knowing. In J. Metcalfe \& A. P. Shimamura (Eds.), Metacognition: Knowing about knowing (pp. 115-136). Cambridge, MA: MIT Press.

Koriat, A., \& Lieblich, I. (1974). What does a person in a "TOT" state know that a person in a "don't know" state doesn't know. Memory \& Cognition, 2, 647-655.

Koriat, A., \& LiEBLICH, I. (1977). A study of memory pointers. Acta Psychologica, 41, 151-164.

KRINSKY, R., \& NELSON, T. O. (1985). The feeling of knowing for different types of retrieval failure. Acta Psychologica, 58, 141-158.

LEONESIO, R. J., \& NELSON, T. O. (1990). Do different metamemory judgments tap the same underlying aspects of memory? Journal of Experimental Psychology: Leaning, Memory, \& Cognition, 16 464-470.

LovelaCE, E. A. (1984). Metamemory: Monitoring future recallability during study. Journal of Experimental Psychology: Learning, Memory, \& Cognition, 10, 756-766

Lupker, S. J., HARbluk, J. L., \& PATrick, A. S. (1991). Memory for things forgotten. Journal of Experimental Psychology: Learning, Memory, \& Cognition, 17, 897-907.

MANDLER, G. (1980). Recognizing: The judgment of previous occurrence. Psychological Review, 87, 252-271.

Mazzoni, G., \& Cornoldi, C. (1993). Strategies in study time allocation: Why is study time sometimes not effective? Journal of Experimental Psychology: General, 122, 47-60.

Mazzoni, G., Cornoldi, C., \& Marchitelli, G. (1990). Do memorability ratings affect study-time allocation? Memory \& Cognition, 18, 196-204.

MetCalfe, J. (1993). Novelty monitoring, metacognition and control in a composite holographic associative recall model: Interpretations for Korsakoff amnesia. Psychological Review, 100, 3-22.

MetCalfe, J. (1994). Novelty monitoring, metacognition, and frontal lobe dysfunction; Implications of a computational model of memory. In J. Metcalfe \& A. P. Shimamura (Eds.), Metacognition: Knowing about knowing (pp. 137-156). Cambridge, MA: MIT Press.

Metcalfe, J., Schwartz, B. L., \& Joaquim, S. G. (1993). The cue familiarity heuristic in metacognition. Journal of Experimental Psychology: Learning, Memory, \& Cognition, 19, 851-861.

Metcalfe, J., \& Shimamura, A. P. (1994). Metacognition: Knowing about knowing. Cambridge, MA: MIT Press.

MEyer, A. S., \& Bock, K. (1992). The tip-of-the-tongue phenomenon: Blocking or partial activation? Memory \& Cognition, 20, 715-726.

Miner, A. C., \& Reder, L. M. (1994). A new look at feeling of knowing: Its metacognitive role in regulating question answering. In J. Metcalfe \& A. P. Shimamura (Eds.), Metacognition: Knowing about knowing (pp. 47-70). Cambridge, MA: MIT Press.

NARENS, L., JAMESON, K. A., \& LeE, V. A. (1994). Subthreshold priming and memory monitoring. In J. Metcalfe \& A. P. Shimamura (Eds.), Metacognition: Knowing about knowing (pp. 71-92). Cambridge, MA: MIT Press.

Nelson, T. O. (1988). Predictive accuracy of the feeling of knowing across different criterion tasks and across different subject populations and individuals. In M. Gruneberg, P. Morris, \& R. Sykes (Eds.), Practical aspects of memory: Current research and issues (Vol. 1 , pp. 190-196). New York: Wiley.

NELson, T. O. (1992). Metacognition: Core readings. Boston: Allyn \& Bacon.

NeLson, T. O. (1993). Judgments of learning and the allocation of study time. Journal of Experimental Psychology: General, 122, 269-273.

NELSON, T. O., \& Dunlosky, J. (1991). When people's judgments of learning (JOLs) are extremely accurate at predicting subsequent recall: The "delayed-JOL effect." Psychological Science, 2, 267-270.

Nelson, T. O., \& Dunlosky, J. (1992). How shall we explain the delayed-judgment-of-learning effect? Psychological Science, 3, 317 318 .
Nelson, T. O., Gerler, D., \& Narens, L. (1984). Accuracy of feelingof-knowing judgments for predicting perceptual identification and relearning. Journal of Experimental Psychology: General, 113, 282300.

Nelson, T. O., \& LeONesio, R. J. (1988). Allocation of self-paced study time and the 'labor-in-vain effect.' Journal of Experimental Psychology: Learning, Memory, \& Cognition, 14, 476-486.

Nelson, T. O., Leonesio, R. J., Landwehr, R. S., \& NARENS, L. (1986). A comparison of three predictors of an individual's memory performance: The individual's feeling of knowing versus the normative feeling of knowing versus base-rate item difficulty. Journal of Experimental Psychology: Learning, Memory, \& Cognition 12, 279-287.

Nelson, T. O., Leonesio, R. J., Shimamura, A. P., Landwehr, R. S., \& NARENS, L. (1982). Overlearning and the feeling of knowing. Journal of Experimental Psychology: Learning, Memory, \& Cognition, 8, 279-288.

Nelson, T. O., \& Narens, L. (1980a). A new technique for investigating the feeling of knowing. Acta Psychologica, 46, 69-90.

Nelson, T. O., \& Narens, L. (1980b). Norms of 300 generalinformation questions: Accuracy of recall, latency of recall, and feeling-of-knowing ratings. Journal of Verbal Learning \& Verbal Behavior, 19, 338-368.

Nelson, T. O., \& Narens, L. (1990). Metamemory: A theoretical framework and new findings. In G. Bower (Ed.), The psychology of learning and motivation (Vol. 26, pp. 125-141). San Diego, CA; Academic Press.

Nelson, T. O., \& NARENS, L. (1994). Why investigate metacognition? In J. Metcalfe \& A. P. Shimamura (Eds.), Metacognition: Knowing about knowing (pp. 1-26). Cambridge, MA: MIT Press.

RAJARAM, S. (1993). Remembering and knowing: Two means of access to the personal past. Memory \& Cognition, 21, 89-102.

Reason, J. T., \& LuCAs, D. (1984). Using cognitive diaries to investigate naturally occurring memory blocks. In J. Harris \& P. E. Morris (Eds.), Everyday memory, actions, and absent mindedness (pp. 5370). London: Academic Press.

REDER, L. M. (1987). Selection strategies in question answering. Cog nitive Psychology, 19, 90-138.

REDER, L. M. (1988). Strategic control of retrieval strategies. In G. Bower (Ed.), The psychology of learning and motivation (Vol. 22, pp. 227-259). San Diego, CA: Academic Press.

REDER, L. M., \& Ritter, F. E. (1992). What determines initial feeling of knowing? Familiarity with question terms, not with the answer. Journal of Experimental Psychology: Learning, Memory, \& Cognition, 18, 435-451.

Roediger, H. L., III (1974). Inhibiting effects of recall. Memory \& Cognition, 2, 261-269.

Ryan, M. P., Petty, C. R., \& Wenzlaff, R. M. (1982). Motivated remembering efforts during tip-of-the-tongue states. Acta Psychologica, 51, 137-147.

SCHACTER, D. L. (1981). Feeling of knowing and the expression of knowledge from episodic memory. Unpublished doctoral dissertation, University of Toronto.

SCHACTER, D. L. (1983). Feeling of knowing in episodic memory. Journal of Experimental Psychology: Learning, Memory, \& Cognition, 9, 39-54.

SCHACTER, D. L., \& Worling, J. R. (1985). Attribute information and the feeling of knowing. Canadian Journal of Psychology, 39, 467475.

Schwartz, B. L., \& BJoRK, R. A. (1993, November). Do people understand the relation between retrieval difficulty and subsequent recall? Paper presented at the meeting of the Psychonomic Society, Washington, DC.

SchwartZ, B. L., \& Metcalfe, J. (1992). Cue familiarity but not target retrievability enhances feeling-of-knowing judgments. Journal of Experimental Psychology: Learning, Memory, \& Cognition, 18, 1074-1083.

Schwartz, B. L., \& Metcalfe, J. (1994). Methodological problems and pitfalls in the study of human metacognition. In J. Metcalfe \& A. P. Shimamura (Eds.), Metacognition: Knowing about knowing (pp. 93-114). Cambridge, MA: MIT Press.

Shimamura, A. P. (1994). The neuropsychology of metacognition. In 
J. Metcalfe \& A. P. Shimamura (Eds.), Metacognition: Knowing about knowing (pp. 253-276). Cambridge, MA: MIT Press.

Shimamura, A. P., \& Squire, L. R. (1986). Memory and metamemory: A study of the feeling-of-knowing phenomenon in amnesic patients. Journal of Experimental Psychology: Leaning, Memory, \& Cognition, 12, 452-460.

Slamecka, N. J., \& Graf, P. (1978). The generation effect: Delineation of a phenomenon. Journal of Experimentai Psychology: Human Learning \& Memory, 4, 592-604.

SмIтH, S. M. (1994). Frustrated feelings of imminent recall: On the tip-of-the-tongue. In J. Metcalfe \& A. P. Shimamura (Eds.), Metacognition: Knowing about knowing (pp. 27-46). Cambridge, MA: MIT Press.

Smith, S. M., Brown, J. M., \& Balfour, S. P. (1991). TOTimals: A controlled experimental method for observing tip-of-the-tongue states. Bulletin of the Psychonomic Society, 29, 445-447.

SPellman, B. A., \& BJork, R. A. (1992). When predictions create reality: Judgments of learning may alter what they are intended to assess. Psychological Science, 3, 315-316.

Tulving, E. (1983). Elements of episodic memory. New York: Oxford University Press, Clarendon Press.

Tulving, E., \& Pearlstone, Z. (1966). Availability versus accessibility of information in memory for words. Journal of Verbal Learning \& Verbal Behavior, 5, 381-391.
UNDERWoOD, B. J. (1966). Individual and group predictions of item difficulty for free learning. Journal of Experimental Psychology, 71, 673-679.

Wellman, H. M. (1977). Tip of the tongue and feeling of knowing experiences: A developmental study of memory monitoring. Child Development, 48, 13-21.

WidNER, R. L., JR., \& SMith, S. M. (1993, November). Imminence and familiarity in tip-of-the-tongue and feeling-of-knowing reports. Paper presented at the meeting of the Psychonomic Society, Washington, DC.

YANIV, I., \& MEYER, D. E. (1987). Activation and metacognition of inaccessible stored information: Potential bases for incubation effects in problem solving. Journal of Experimental Psychology: Learning. Memory, \& Cognition, 13, 187-205.

\section{NOTE}

1. A fourth motivation, not discussed by Koriat, exists in the connection between metamnemonic judgments and the control of behavior (Mazzoni \& Cornoldi, 1993; Mazzoni et al., 1990; Nelson \& Leonesio, 1988; Nelson \& Narens, 1990, 1994; Reder \& Ritter. 1992).

(Manuscript received September 10, 1993; revision accepted for publication May 17, 1994.) 